\title{
STRATEGI MANAJEMEN KEPEMIMPINAN KEPALA SEKOLAH DALAM MENINGKATKAN KUALITAS KINERJA PENDIDIK DAN TENAGA KEPENDIDIKAN
}

\author{
Muflikha*, Budi Haryanto** \\ Universitas Muhammadiyah Sidoarjo \\ *muflikha1112@gmail.com \\ *budihar65@yahoo.co.id
}

\begin{abstract}
This paper aims to analyze the Principal's leadership management strategy in improving the Performance of Educators and Education Personnel. The Headmaster Leadership management strategy is one of the keys to success for improving the quality of performance of educators and education personnel. Increasing the quality of the performance of educators and education personnel will have a significant impact on the educational process and the achievement of desired educational goals. This paper uses a descriptive qualitative approach that seeks to describe the form of leadership management strategies for school principals in order to improve the quality of educational performance and education personnel. The results of this study indicate that (1) the Principal's management strategy has a very important role in improving the performance of educators and education personnel. (2) the quality of the performance of educators and education personnel has an impact on improving the quality of learning and achieving educational goals to the fullest
\end{abstract}

Keywords: Principal Leadership Management Strategy, Teacher Performance and Education Personnel

\begin{abstract}
Abstrak: Tulisan ini bertujuan untuk menganalisis Strategi Manajemen Kepemimpinan Kepala Sekolah dalam Meningkatkan Kinerja Pendidik dan Tenaga Kependidikan. Strategi Manajemen Kepemimpinan Kepala Sekolah menjadi salah satu kunci sukses bagi peningkatan kualitas kinerja pendidik dan tenaga kependidikan. Meningkatnya kualitas kinerja pendidik dan tenaga kependidikan akan memberikan dampak yang signifikan bagi proses pendidikan dan tercapainya tujuan pendidan yang diinginkan. Tulisan ini menggunakan pendekatan deskriptif kualitatif yang merusaha memaparkan bentuk strategi manajemen kepemimpinan seorang Kepala Sekolah dalam rangka meningkatkan kualitas kinerja pendidikan dan tenaga kependidikan. Hasil penelitian ini menunjukkan bahwa (1) strategi manajemen Kepala Sekolah memiliki peranan yang sangat penting dalam meningkatkan kinerja pendidik dan tenaga kependidikan. (2) kualitas kinerja pendidik dan tenaga kependidikan
\end{abstract}


memberikan pengaruh bagi meningkatnya kualitas pembelajaran dan tercapainya tujuan pendidikan secara maksimal.

Kata Kunci: Manajemen Kepemimpinan Kepala Sekolah, Kinerja Pendidik dan Tenaga Kependidikan

\section{PENDAHULUAN}

Secara umum pendidikan merupakan suatu upaya yang dilakukan secara perorangan maupun lembaga untuk merancang masa depan setiap manusia sehingga konsep dan implementasinya harus benar - benar mempertimbangkan seluruh aspek kehidupan manusia baik sosial, budaya, ekonomi, pendidikan politik bahkan agama sekalipun. Dalam Undang - undang RI Nomor 20 tahun 2003 pasal 3 dijelaskan bahwa Pendidikan Nasional berfungsi mengembangkan kemampuan serta membentuk watak dan peradaban bangsa yang bermartabat dalam rangka mencerdaskan kehidupan bangsa, bertujuan untuk berkembangnya potensi peserta didik agar menjadi manusia yang beriman dan bertakwa kepada Tuhan yang maha Esa, berakhlak mulia, berilmu, sehat, cakap, kreatif, dan menjadi warga Negara yang demokratis dan bertanggung jawab. ${ }^{1}$ sementara pada sisi yang lain perkembangan IPTEK (sains) yang semakin tidak terbendung serta proses perubahan dan perkembangan sosial budaya masyarakat, adat istiadat serta masih belum meratanya kualitas SDM (Sumber Daya Manusia) semakin menambah betapa pentingnya sebuah kebijakan yang berisi sekumpulan strategi baru untuk meningkatkan kualitas pendidikan yang dicita-citakan.

Secara fungsional pendidikan memegang peran yang sangat penting dalam pembangunan manusia dan bangsa oleh karena itu sebuah lembaga pendidikan dituntut agar dapat melaksanakan fungsi manajemen sekolah dengan baik. Salah satunya melalui strategi manajemen kepala sekolah. Robbin mengemukakan bahwa, "leadership is ability to influence a group toward the achievment goals". ${ }^{2}$ Salah satu fungsi kepemimpinan adalah untuk mempengaruhi seseorang / kelompok dalam rangka mncapai suatu target tujuan yang diinginkan. Oleh karena itu proses kepemimpinan harus dilakukan dalam rangka mengkoordinasikan dan mengarahkan baik secara

\footnotetext{
${ }^{1}$ Undang - undang Nomor 20 tahun 2003 tentang System Pendidikan Nasional

${ }^{2}$ Rohiat, 2008. Kecerdasan Emosional Kepemimpinan Kepala Sekolah. Bandung: PT Refika Aditama.
} 
perorarangan maupun kelompok untuk mencapai suatu tujuan yang telah ditetapkan, sehingga seorang pemimpin membutuhkan sutua gaya dan tipe tertentu guna mempermudah dan memuluskan langka serta proses kepemimpinan.

Strategi manajemen Kepemimpinan Kepala Sekolah harus dikonstruksi berdasarkan perubahan dan perkembangan lingkungan masyarakatnya dengan tetap mempertimbangkan aspek kebersamaan dan keragamaan, sehingga mampu mengadakan program-program baru yang mampu meningkatkan kualitas pendidikan dan tenaga kependidikan sertab harus selalu di evaluasi bahkan diperbaharui. Kebanyakan menajamen kepala sekolah (sekolah negeri) cenderung bersifat administratif dan sekedar melaksanakan kebijakan dari atas ke bawah, tanpa mempertimbangkan proyek peningkatan dan pengembangan yang seharusnya selalu menjadi agenda utama bagi seorang pemimpin. Oleh karena itu pembinaan yang dilakukan seorang Kepala Sekolah mestinya tidak hanya bersifat administratif tetapi lebih pada pengembangan dan peningkatan kualitas kompetensi pendidikan dan tenaga kependidikan. Terdapat 4 kompetensi yang harus dikembangkan terhadap seorang guru (pendidik) yaitu kompetensi pedagogik, kepribadian, sosial dan prefesional. Sehingga strategi manajemen kepemimpinan kepala sekolah menjadi kunci keberhasilan guru atau pendidikand an tenaga kependidikan.

\section{METODE PENELITIAN}

Pendekatan yang digunakan dalam penelitian ini adalah pendekatan Deskriptif kualitatif yang berupaya memperoleh dan menghimpun serta mengolah bahkan menganalisis dan mendefinisikan data secara kualitatif. ${ }^{3}$ Menurut Danim bahwa Pendekatan kualitatif deskriptif yaitu suatu prosedur penelitian yang menghasilkan data deskriptif berupa kata-kata yang tertulis atau lisan dari orang-orang dan perilaku yang dapat diamati. ${ }^{4}$ Data penelitian dikumpulkan sebagai sumber data langsung kemudian diklasifikasikan dan dianalisis berdasarkan tehnik content analysis, ${ }^{5}$ yaitu suatu analisis data yang dilakukan secara cermat, obyektif dan sistematis. Sehingga penelitian ini

\footnotetext{
${ }^{3}$ Bachtiar, W. Metodologi Penelitian Imu Dakwah. Cet.ke-1. Wacana Ilmu, Logos Jakarta. 1997.

${ }^{4}$ Sudarwan Danim, Menjadi Peneliti Kualitatif, ( Bandung:Pustaka Setia, 2002), hlm 26

${ }^{5}$ Septiawan Santana K, Menulis Ilmiah: Metode Penelitian Kualitatif, (Jakarta: Yayasan Obor Indonesia, 2007) 28
} 
diharapkan mampu mendiskripsikan, sekaligus menemukan secara menyeluruh dan utuh mengenai Strategi Manajemen Kepemimpinan Kepala Sekolah dalam Meningkatkan kualitas Kinerja Pendidik dan Tenaga Kependidikan.

\section{Konsep Dasar Kepemimpinan}

Kepala sekolah berasal dari dua kata yaitu "Kepala" artinya ketua dan "Sekolah" artinya sebuah lembaga. Jadi pengertyian kepala sekolah adalah sorang pemimpin sekolah atau suatu lembaga di mana lembaga itu sebagai tempat berlangsung kegiatan belajar mengajar dalam arti sebuah proses pendidikan. menurut Mulyasa Kepala sekolah adalah tenaga fungsional guru yang diberi amanat untuk memimpin suatu sekolah dalam menyelenggarakan sroses pendidikan. ${ }^{6}$ Sementara Suhardiman menjelaskan kepala sekolah adalah seorang guru yang diberi mandate untuk menduduki jabatan structural pada sebuah lembaga pendidikan formal. ${ }^{7}$

Berdasarkan pandangan tersebut maka pemimpin dapat diartikan sebagai seseorang yang memiliki kemampuan untuk mempengaruhi orang lain baik pada sisi prilaku maupun sikap dan pola pikirnya. Oleh karena itu dalam sebuah kepemimpinan dibutuhkan suatu karakter yang kuat, tegas, inovatif dan tahan uji, tertancap kuat dalam diri sehingga tercipta kepemimpinan yang kuat dan efektif lagi efisien. Dalam konteks yang lebih jauh sebiuh kepemimpinan menjadi faktor utama dalam sebuah organisasi sehingga berhasil dan tidaknya sebuah organisasi tergantung seberapa sukses misi dan visi kepemimpinan yang dijalankan. Dengan demikian maka kepemimpinan dapat diartikan sebagai suatu kemampuan yang dimiliki seseorang dalam mempengaruhi orang lain untuk mau bekerja sama melakukan suatu tindakan dan perbuatan dalam mencapai tujuan yang telah ditetapkan bersama.

Mulyadi menjelaskan bahwa perilaku dalam menjalankan tugas kepemimpinan meliputi :

1. Pengambilan keputusan.

2. Penguatan kesetiaan pengikutnya.

3. Pengorganisasian yang kuat

4. Pemberdayaan SDM dan sumber daya lainnya.

${ }^{6}$ Mulyasa, H.E. (2015). Manajemen dan Kepemimpinan Kepala Sekolah. Jakarta: PT. Bumi Aksara.

${ }^{7}$ Suhardiman, Budi. (2012). Studi Pengembangan Kepala Sekolah. Jakarta: Rineka Cipta 
5. Tindakan evalusi dan solusi

6. Memberikan reward

7. Pendelegasian wewenang.

8. Pemberian semangat dan motivasi ${ }^{8}$

\section{Manajemen Kepemimpinan Kepala Sekolah}

Dalam kepemimpinan sekolah dibutuhkan dua keterampilan khusus yaitu (1) keterampilan memimpin dan (2) keterampilan mengelola atau yang popular dengan istilah kepemimpinan dan manajerial. Prilaku kepemimpinan dengan segala keterampilan memegang peranan yang sangat penting untuk meningkatkan kualitas sekolah secara umum. Perilaku kepemimpinan yang mendukung terhadap implementasi manajemen kepala sekolah akan lebih mempercepat tercapainya tujuan yang telah dirumuskan bersama. $^{9}$

Suatu kepemimpinan yang tidak disertai dengan keterampilan memimpin dan manajerial maka akan mengurangi tingkat keberhasilan tugas kepemimpinan. ${ }^{10}$ Dengan kata lain bahwa suatu kepemimpinan harus didasari oleh kemampuan manajerial serta prilaku pribadi yang mampu mempengaruhi bahkan menentukan tercapainya tujuan dari kepemimpinan tersebut, karena sikap dan prilaku seorang pemimpin akan memberikan corak dan sangat berpengaruh terhadap prilaku karyawan serta pencapaian keberhasilan. Oleh karena itu strategi manajemen mutu yang terintegrasi dengan prilaku dan kebijakan pemimpin menjadi penting untuk di implementasikan. Tinggi dan rendahnya kualitas strategi manajemen mutu akan sangat menetukan kualitas kinerja dan hasil yang akan dicapai baik dalam jangka pendek maupun jangka panjang.

8 Karwati, Euis. (2016). Kinerja dan Profesionalisme Kepala Sekolah Membangun Sekolah yang Bermutu. Bandung: Alfabeta.

9 Mulyasa H.E (2013). Menjadi Kepala Sekolah Profesional. Bandung: PT Remaja Rodaskarya Offset.

${ }^{10}$ Basri, Hasan. (2014) Kepemimpinan Kepala Sekolah. Bandung: CV. Pustaka Setia 


\section{Tipe-tipe Kepemimpinan Kepala Sekolah yang Ideal}

Seorang pemimpin akamn mampu menjalankan tugas kepemimpinannya jika dia mampu memberdayakan SDM dan sumber daya lainnya yang terkait sesuai dengan standart mutu yang ada. ${ }^{11}$ Berikut beberapa tipe kepemimpinan yang umum dipraktekkan dalam sebuah organisasi termasuk sekolah / lembaga pendidikan, yaitu:

1. Tipe Kepemimpinan Kharismatis

Tipe kepemimpinan karismatis memiliki kekuatan energi, daya tarik dan pembawaan yang luar biasa untuk mempengaruhi orang lain baik secara perorangan ataupun kelompok. ${ }^{12}$

2. Tipe Kepemimpinan Militeristik

Tipe kepemimpinan militeristik (otoriter), sifat-sifat dari tipe kepemimpinan militeristik (otoriter), yaitu:

a. Lebih banyak menggunakan sistem perintah/komando, keras dan kaku dan seringkali kurang bijaksana

b. Menghendaki kepatuhan mutlak dari bawahan

c. Sangat menyenangi formalitas, upacara-upacara serimonial.

d. Menuntut adanya disiplin yang keras dan kaku dari bawahannya

e. Tidak menghendaki saran, usul dan kritikan dari bawahannya

f. Komunikasi hanya berlangsung searah. ${ }^{13}$

3. Tipe Kepemimpinan Otokratis (Outhoritative, Dominator)

Kepemimpinan otokratis adalah tipe kepemimpinan yang memandang bahwa kepemimpinan itu mutlak dan final serta harus dipatuhi oleh semua pihak, sehingga tipe ini juga dikenal kenal dengan tipe kepemimpinan individualistic hanya menganggap pendapat dan prinsipnya yang paling benar. ${ }^{14}$

\footnotetext{
${ }^{11}$ Sagala, Syaiful. (2007). Manajemen Strategi dalam Peningkatan Mutu Pendidikan. Bandung: Alfabeta, 12 Suparlan. 2014. Manajemen Berbasis Sekolah dari Teori sampai dengan praktik. Jakarta : PT. Bumi Angsara. 17

${ }^{13}$ Mulyas, H.E (2014). Manajemen Berbasis Sekolah. Bandung: PT Remaja Rodaskarya Offset.. 23

${ }^{14}$ Mulyasa H.E (2014). Manajemen Berbasis Sekolah. Bandung: PT Remaja Rodaskarya Offset.27
} 
4. Tipe Kepemimpinan Administratif/Eksekutif

Kepemimpinan tipe administratif ialah kepemimpinan yang lebih menekankan pada manajemen administrative serta mampu menyelenggarakan tugas-tugas administrasi secara efektif.. ${ }^{15}$

5. Tipe Kepemimpinan Demokratis

Kepemimpinan demokratis berorientasi pada manusia dan memberikan bimbingan yang efisien kepada para pengikutnya. ${ }^{16}$

\section{Strategi Manajemen Kepemimpinan dalam Meningkatkan kualitas Kinerja Pendidik dan Tenaga Kependidikan}

Kepemimpinan adalah proses untuk mempengaruhi individu atau kelompok agar secara sadar dan secara harmonis bekerja untuk mencapai tujuan organisasi yang telah ditetapkan. Pengakuan terhadap pentingnya strategi kepemimpinan dalam organisasi telah menjadi dasar utama dalam menganalisis peran dan fungsinya dalam meningkatkan kualitas kinerja bawahannya. Sedangkan kualitas kinerja adalah standart kinerja (pokok) yang telah disepakati bersama dalam sebuah organisasi (SOP). Berikut analisis singkat tentang kinerja menurut para ilmuan:

Tabel 1 Pendapat Para Pakar tentang Pengertian Kinerja ${ }^{17}$

\begin{tabular}{|l|l|l|}
\hline No & \multicolumn{1}{|c|}{ Pengertian Kinerja } & \multicolumn{1}{|c|}{ Pendapat } \\
\hline 1. & $\begin{array}{l}\text { Performance diartikan sebagai hasil pekerjaan, } \\
\text { atau pelaksanaan tugas pekerjaan }\end{array}$ & $\begin{array}{l}\text { Pariata Westra } \\
\text { et al. 1977:246). }\end{array}$ \\
\hline 2. & $\begin{array}{l}\text { kinerja adalah proses kerja dari seorang } \\
\text { individu untuk mencapai hasil-hasil tertentu, }\end{array}$ & $\begin{array}{l}\text { Bateman } \\
(1992: 32)\end{array}$ \\
\hline 3. & $\begin{array}{l}\text { Prestasi Kerja atau penampilan kerja } \\
\text { (performance) diartikan sebagai ungkapan } \\
\text { kemampuan yangdisasari oleh pengetahuan, sikap, } \\
\text { dan ketrampilan dan motivasi dalam menghasilkan }\end{array}$ & \\
\hline
\end{tabular}

15 Mazarei, Ibrahim et al. 2013. "The Relationships between Servant Leadership Style and Organizational Commitment”. Scholars Research Library. Archives of Applied Science Research, 5

${ }^{16}$ Ivancevich, John M. (2007) Human Resource Management. Asia: Mcgraw-Hill International Edition

17 Washington, Rynetta et al. 2006. "Individual differences in servant leadership: the roles of values and personality”. Leadership \& Organization Development Journal. Vol. 27 No. 8. pp. 700-716 


\begin{tabular}{|l|l|l|} 
& sesuatu, & \\
\hline 4. & $\begin{array}{l}\text { Performance is defined as the record of outcomes } \\
\text { produced on a specified job function or activity } \\
\text { during a specific time periode }\end{array}$ & $\begin{array}{l}\text { Bernardin dan } \\
\text { Russel } \\
\text { dalam Ahmad } \\
\text { S Ruky } \\
(2001: 15)\end{array}$ \\
\hline 5. & $\begin{array}{l}\text { Kinerja (prestasi kerja) adalah hasil kerja secara } \\
\text { kualitas dan kuantitas yang dicapai oleh seorang } \\
\text { pegawai dalam melaksanakan tugasnya sesuai } \\
\text { dengan tanggung jawab yang diberikan kepadanya. }\end{array}$ & $\begin{array}{l}\text { A. Anwar Prabu } \\
\text { Mangunegara } \\
\text { (2001:67) }\end{array}$ \\
\hline
\end{tabular}

Dari beberapa pengetian kinerja di atas maka dapat disimpulkan bahwa kinerja adalah merupakan suatu kemampuan kerja atau prestasi kerja yang diperlihatkan oleh seorang pegawai dalam memperoleh hasil kerja yang optimal. Dengan kata lain bahwa kinerja mempunyai derifasi pengertian akan adanya suatu tindakan yang ditampilkan oleh seseorang dalam melaksanakan aktivitas tertentu. Faktor - faktor yang mempengaruhi pencapaian kinerja adalah faktor kemampuan (Ability) dan faktor motivasi (Motivation). ${ }^{18}$

Hal ini sesuai dengan pendapat Keith Davis yang dikutip oleh A. Anwar Sobirin PM mengemukakan bahwa faktor-faktor yang mempengaruhi kinerja adalah :

1. Faktor Motivasi

Motivasi terbentuk dari sikap seseorang dalam menghadapi situasi kerja. Motivasi merupakan kondisi yang menggerakan seseorang yang terarah untuk mencapai tujuan organisasi sehingga seseorang akan meraih kinerja maksimal jika ia memiliki motivasi tinggi.

2. Faktor Kemampuan

Secara psikologis kemampuan (Ability) pegawai terdiri dari kemampuan potensi $(I Q)$ dan kemampuan reality (Knowledge + Skill). Artinya pegawai yang memiliki IQ di atas rata-rata (IQ 110-120) dengan pendidikan yang memadai untuk jabatannya dan terampil dalam mengerjakan pekerjaan sehari-hari,

18 Sulistyani, Ambar Teguh dan Rosidah, 2009, Manajemen Sumber Daya Manusia:Konsep, Teori dan Pengembangan dalam Konteks Organisasi Publik, Edisi 2,Graha Ilmu, Yogyakarta 
maka ia akan lebih mudah mencapai kinerja yang diharapkan. Oleh karena itu, pegawai perlu ditempatkan pada pekerjaan yang sesuai dengan keahliannya. ${ }^{19}$

Beberapa Strategi Manajerial Kepala Sekolah dalam meningkatkan Kinerja pendidikan dan tenaga kependidikan, sebagaimana terdiskripsikan dalam tabel berikut:

\begin{tabular}{lll} 
NO & $\begin{array}{c}\text { Tabel } 2 \text { Strategi Manajerial Kepala Sekolah } \\
\text { 20 }\end{array}$ & \multicolumn{1}{c}{ Ciri / aspeknya/strategi } \\
\hline 1 & Partisipatif & Pemimpin menyediakan waktu dan \\
& & $\begin{array}{l}\text { kesempatan untu serap aspirasi } \\
\text { dengan bawahannya }\end{array}$ \\
& & Berorientasi pada perubahan \\
& & Berbasis mitra dan sahabat \\
\hline 2 & Maximum Leadership & Pendekatan strategi \\
& & Pendekatan asset manusia \\
& & Pendekatan keahlian \\
& & Pendekatan control \\
& & Pendekatan agen perubahan \\
\hline 3 & Principle Centered & Berorientasi pada pelanggan \\
& Landership & Mementingkan kapabilitas \\
\hline 4 & Instant Leadership & Penyusunan prioritas \\
& & Integriras \\
& & Berbasis perubahan \\
& & Strategi Pelanggan \\
& & Strategi pemberdayaan \\
& & Strategi banding resiko \\
& &
\end{tabular}

19 Anwar Sobirin PM. 1999. Memahami Arti dan Makna Budaya Organisasi, SINERGI : kajian Bisnis dan Manajemen vol. 2 No. 2, 1999 Hal 189-215

${ }^{20}$ Usman, Husaini. (2009) Manajemen Teori Praktik dan Riset Pendidikan. Jakarta: Bumi Aksara 
Strategi manajemen kepemimpinan di atas kemudian terimplementasikan dalam sebuah kebijakan akan peningkatan kualitas kinerja peserta didik. strategi tersebut dapat ditempuh dengan cara - cara berikut ini :

Tabel 3 Implementasi strategi Manajemen ${ }^{21}$

\section{No Cara / Strategi Uraian}

\begin{tabular}{|c|c|c|}
\hline 1 & Mendengar (listening) & $\begin{array}{l}\text { Kepala sekolah mendengarkan apa saja yang } \\
\text { dikemukakan guru, bisa berupa kelemahan, kesulitan, } \\
\text { masalah dan apa saja yang dialami guru, termasuk yang } \\
\text { ada kaitannya dengan peningkatan profesionalisme } \\
\text { guru }\end{array}$ \\
\hline 2 & $\begin{array}{l}\text { Mengklarifikasi } \\
\text { (clarifying) }\end{array}$ & $\begin{array}{l}\text { Kepala sekolah memperjelas mengenai apa yang } \\
\text { dimaksudkan oleh guru dalam mengklarifikasi kepala } \\
\text { madrasah memperjelas apa yang diinginkan guru } \\
\text { dengan menanyakan kepadanya }\end{array}$ \\
\hline 3 & $\begin{array}{l}\text { Mendorong } \\
\text { (encouraging) }\end{array}$ & $\begin{array}{l}\text { Kepala madrasah mendorong guru agar mau } \\
\text { mengemukakan kembali mengenai sesuatu hal } \\
\text { bilamana masih dirasakan belum jelas. }\end{array}$ \\
\hline
\end{tabular}

4 Mempresentasikan Kepala sekolah mencoba mengemukakan persepsinya (presenting) mengenai apa yang dimaksudkan oleh guru.

\begin{tabular}{lll}
\hline 5 & $\begin{array}{l}\text { Memecahkan } \\
\text { masalah } \\
\text { solving) }\end{array}$ & $\begin{array}{l}\text { kepala sekolah bersama-sama dengan guru } \\
\text { memecahkan masalah-masalah yang dihadapi guru. }\end{array}$ \\
\hline 6 & Berunding (confer) & Kepala sekolah dan guru membangun kesepakatan \\
& & mengenai tugas yang harus dilaksanakan masing- \\
& &
\end{tabular}

7 Mendemonstrasikan kepala sekolah mendemonstrasikan hal-hal tertentu (demonstrate) dengan maksud agar dapat diamati dan ditirukan oleh bawahan

${ }^{21}$ Ismail, I, 2008, "Pengaruh Budaya Organisasi Terhadap Kepemimpinan dan Kinerja Karyawan Pemerintah Kabupaten-Kabupaten di Madura”, EKUITAS, 36 
8 Mengarahkan kepala sekolah mengerahkan guru melakukan hal-hal (directing) tertentu

\begin{tabular}{cll}
\hline 9 & $\begin{array}{l}\text { Menstandarkan } \\
\text { (standardize) }\end{array}$ & $\begin{array}{l}\text { Kepala sekolah mengadakan penyesuaian-penyesuaian } \\
\text { bersama dengan guru }\end{array}$ \\
\hline 10 & Memberikan & Memberikan penguat dengan menggambarkan kondisi- \\
& penguat (strengthen) & kondisi yang menguntungkan bagi pembinaan guru
\end{tabular}

Tabel 4 Pelaksanaan Strategi Manajemen Kepala Sejolah ${ }^{22}$

Strategi / Tipologi kepemimpinan

\begin{tabular}{|c|c|c|c|}
\hline $\mathrm{NO}$ & Manajemen & Bentuk Sikap & Gaya Kepemimpinan \\
\hline 1 & $\begin{array}{l}\text { Perilaku } \\
\text { Keseharian }\end{array}$ & $\begin{array}{l}\text { Perhatian, terbuka, periang, tegas, } \\
\text { bijaksana disiplin dan komitmen } \\
\text { serta memiliki emosi yang stabil. }\end{array}$ & Visioner - Demokrasi \\
\hline 2 & $\begin{array}{l}\text { Pendelegasian } \\
\text { Tugas }\end{array}$ & $\begin{array}{l}\text { Pendelegasian tugas dilakukan secara } \\
\text { adil, merata dan disesuaikan dengan } \\
\text { bidang keahlian, memberikan } \\
\text { pengarahan terlebih dahulu, } \\
\text { pemberian tanggung jawab dengan } \\
\text { melibatkan dan memberdayakan } \\
\text { seluruh personil Sekolah }\end{array}$ & $\begin{array}{l}\text { Demokrasi } \\
\text { Transaksional }\end{array}$ \\
\hline 4 & $\begin{array}{l}\text { Pengambilan } \\
\text { Keputusan }\end{array}$ & $\begin{array}{l}\text { Bersama/mufakat dengan } \\
\text { mengundang seluruh personil } \\
\text { sekolah, pengambilan keputusan } \\
\text { bersama melalui kegiatan rapat } \\
\text { dengan memberikan informasi dari } \\
\text { lembaga yang menaungi sekolah } \\
\text { (Dinas pendidikand dan UPTD) } \\
\text { untuk kemudian dipecahkan/dicari } \\
\text { solusi secara bersama, melakukanm }\end{array}$ & $\begin{array}{l}\text { Demokrasi } \\
\text { Transaksional }\end{array}$ \\
\hline
\end{tabular}


koordinasi dengan pembagian tugas,

kepala sekolah selalu terlibat dalam

pengambilan keputusan.

\begin{tabular}{|c|c|c|c|}
\hline 5 & Pengawasan & $\begin{array}{l}\text { Guru: supervise administrasi dan } \\
\text { supervise pembelajaran (kunjungan } \\
\text { kelas) Tenaga kependidikan (staf): } \\
\text { melakukan kontrol/pemantaua n } \\
\text { secara langsung dengan menanyakan } \\
\text { progress dari tugas yang telah } \\
\text { dikerjakan. }\end{array}$ & Supervisor Visioner \\
\hline & $\begin{array}{l}\text { Pengembangan } \\
\text { Sekolah }\end{array}$ & $\begin{array}{l}\text { Memiliki antusiasme dalam } \\
\text { mengembangkan sekolah, seperti } \\
\text { mengembangkan ekstrakurikuler, } \\
\text { mengembangkan pembelajaran } \\
\text { dengan berinovasi membuat } \\
\text { program tambahan. }\end{array}$ & $\begin{array}{l}\text { Visioner } \\
\text { Transformasional }\end{array}$ \\
\hline & Komunikasi & $\begin{array}{l}\text { Komunikasi terbuka, komunikasi } \\
\text { dua arah dengan menerima } \\
\text { konsultasi, ide-ide dan menerima } \\
\text { dan memberi kritik dan saran. }\end{array}$ & Demokrasi \\
\hline & Motivasi & $\begin{array}{l}\text { Memenuhi kebutuhan guru dan } \\
\text { tenaga kependidikaan seperti makan } \\
\text { dan minum, memberikan rasa aman, } \\
\text { memberikan kenyamanan, } \\
\text { menghargai setiap individu dengan } \\
\text { memberikan dorongan semangat, } \\
\text { memenuhi kebutuhan pembelajaran. }\end{array}$ & $\begin{array}{l}\text { Demokrasi } \\
\text { Path goal }\end{array}$ \\
\hline & Penghargaan & $\begin{array}{l}\text { Memberikan pujian dan ucapan } \\
\text { terimakasih }\end{array}$ & Demokrasi \\
\hline
\end{tabular}


Strategi manajemen pendidik dan tenaga kependidikan (SDM) adalah merupakan proses kependidikan yang membutuhkan waktu cukup panjang dalam upaya pencapaian tujuan pendidikan, oleh karena itu harus diselenggarakan melalui tahapan-tahapan berikut :

1. Perencanaan (Planning)

Kegiatan ini dilaksanakan sesuai dengan kebutuhan, kemampuan dan standart yang dirumuskan bersama oleh pihak sekolah (kepala sekolah)

2. Pengembangan / Pelaksanaan (implementation)

Kegiatan pengembangan tenaga pendidik dan tenaga kependidikan dilaksanakan guna peningkatan kualitas kinerja stakeholder pendidikan agar mampu melaksanakan tugasnya dengan efektif serta dapat berkompetisi dalam memajukan pendidikan.

3. Evaluasi (evaluation)

Peningkatan kualitas kinerja tenaga pendidik dan tenaga kependidikan dilaksanakan guna mengetahui prestasi kerja, kecakapan dalam melaksanakan tugas pokok dan fungsi serta meningkatkan kemampuan dalam bekerja sehingga dapat bermanfaat bagi pengembangan sekolah secara umum. ${ }^{23}$

Oleh karena itu implikasi dari strategi manajemen Kepemimpinan Kepala Sekolah dalam meningkatkan kualitas Kinerja Pendidik dan Tenaga Kependidikan dapat dirumuskan dalam perspektif sebagai berikut :

1. Kepala Sekolah dapat menyelenggarakan proses pendidikan sesuai tujuan pendidikan secara umum secara efektif dan efisien.

2. Kepala Sekolah dapat memperoleh suber daya pendidik dan tenaga kependidikan yang diharapkan mampu membangun serta mewujudkan visi dan misi sekolah secara optimal.

3. Pendidik dan tenaga kependidikan akan memiliki kompetensi serta pengalaman yang baik dan luas serta dapat dijadikan sebagai panutan yang mendidik bagi peserta didik.

${ }^{23}$ Mas'ud, Fuad, 2004, Survai Diagnosis Organisasional, Badan Penerbit Universitas Diponegoro, Semarang 
4. Kegiatan evaluasi kinerja dapat dijadikan sebagai tolak ukur untuk memperbaiki diri (Pendidik dan tenaga kependidikan) maupun kegaiatan pembelajaran di masa yang akan datang.

\section{KESIMPULAN}

Berangkat dari kajian ilmiah diatas maka dapat diambil kesimpulan sebagai berikut :

1. Kepemimpinan dalam pendidikan adalah Kemampuan menggerakkan semua personil satuan pendidikan atau sekolah dalam melaksanakan tugas pembelajaran sesuai dengan prinsip-prinsip paedagogik.

2. Strategi manajemen Kepemimpinan Kepala Sekolah adalah suatu usaha yang dilakukan untuk mempengaruhi, mendorong, membimbing, mengarahkan dan menggerakan bahkan memberdayakan guru, staf, siswa, orang tua siswa dan pihak terkait untuk bekerja atau berperan aktif dalam mencapai tujuan pendidikan yang telah ditetapkan.

3. Keterampilan yang dibutuhkan oleh seorang kepala sekolah adalah keterampilan memimpin (leadership) sekaligus keterampilan mengelola (manajerial) Adapun strategi manajemen kepala sekolah dalam meningatkan kualitas kinerja pendidik dan tenaga kependidikan adalah sebagai berikut : 1) Mendengar (listening); 2) Mengklarifikasi (clarifying); 3) Mendorong (encouraging); 4) Mempresentasikan (presenting); 5) Memecahkan masalah (problem solving); 6) Negosiasi (berunding); 7) Mendemonstrasikan; 8) Mengarahkan (directing); 9) Menstandarkan; 10) Memberikan penguat..

\section{DAFTAR PUSTAKA}

Anwar Sobirin PM. 1999. Memahami Arti dan Makna Budaya Organisasi, SINERGI : kajian Bisnis dan Manajemen vol. 2 No. 2, 1999 Hal 189-215

Bachtiar, W. Metodologi Penelitian Ilmu Dakwah. Cet.ke-1. Wacana Ilmu, Logos Jakarta. 1997.

Basri, Hasan. (2014) Kepemimpinan Kepala Sekolah. Bandung: CV. Pustaka Setia 
Hasan Langgulung, 1998. Beberapa Pemikiran Kepemimpinan Pendidikan Islam, Bandung : al-Ma'arif, Cet. II,

Ismail, I, 2008, 'Pengarub Budaya Organisasi Terbadap Kepemimpinan dan Kinerja Karyawan Pemerintab Kabupaten-Kabupaten di Madura", EKUITAS

Ivancevich, John M. (2007) Human Resource Management. Asia: Mcgraw-Hill International Edition

Karwati, Euis. (2016). Kinerja dan Profesionalisme Kepala Sekolah Membangun Sekolah yang Bermutu. Bandung: Alfabeta.

Mas'ud, Fuad, 2004, Survai Diagnosis Organisasional, Badan Penerbit Universitas Diponegoro, Semarang

Mazarei, Ibrahim et al. 2013. "The Relationships between Servant Leadership Style and Organizational Commitment”. Scholars Research Library. Archives of Applied Science Research

Mulyasa, H.E. (2015). Manajemen dan Kepemimpinan Kepala Sekolah. Jakarta: PT. Bumi Aksara.

Mulyasa H.E (2013). Menjadi Kepala Sekolah Profesional. Bandung: PT Remaja Rodaskarya Offset.

Mulyasa, H.E (2014). Manajemen Berbasis Sekolah. Bandung: PT Remaja Rodaskarya Offset.

Rohiat, 2008. Kecerdasan Emosional Kepemimpinan Kepala Sekolah. Bandung: PT Refika Aditama

Sagala, Syaiful. (2007). Manajemen Strategi dalam Peningkatan Mutu Pendidikan. Bandung: Alfabeta,

Septiawan Santana K, Menulis Ilmiah: Metode Penelitian Kualitatif, (Jakarta: Yayasan Obor Indonesia, 2007)

Sudarwan Danim, Menjadi Peneliti Kualitatif, ( Bandung:Pustaka Setia, 2002)

Suhardiman, Budi. (2012). Studi Pengembangan Kepala Sekolah. Jakarta: Rineka Cipta

Sulistyani, Ambar Teguh dan Rosidah, 2009, Manajemen Sumber Daya Manusia:Konsep, Teori dan Pengembangan dalam Konteks Organisasi Publik, Edisi 2,Graha Ilmu, Yogyakarta

Suparlan. 2014. Manajemen Berbasis Sekolah dari Teori sampai dengan praktik. Jakarta : PT. Bumi Angsara.

Undang - undang Nomor 20 tahun 2003 tentang System Pendidikan Nasional

Usman, Husaini. (2009) Manajemen Teori Praktik dan Riset Pendidikan. Jakarta: Bumi Aksara

Wahyudi, (2015). Kepemimpinan Kepala Sekolah dalam Organisasi Pembelajar (Learning Organization). Pontianak: Alfabeta

Washington, Rynetta et al. 2006. "Individual differences in servant leadership: the roles of values and personality". Leadership \& Organization Development Journal. Vol. 27 No. 8. pp. $700-716$ 